Original Article (short paper)

\title{
Relationship between physical fitness and game- related statistics in elite professional basketball players: Regular season vs. playoffs
}

\author{
João Henrique Gomes \\ Universidade São Judas Tadeu, São Paulo, SP, Brasil \\ Renata Rebello Mendes \\ Marcos Bezerra de Almeida \\ Universidade Federal de Sergipe, Sergipe, SE, Brasil \\ Marcelo Callegari Zanetti \\ Universidade São Judas Tadeu, São Paulo, SP, Brasil \\ Gerson dos Santos Leite \\ Universidade Nove de Julho, São Paulo, SP, Brasil \\ Aylton José Figueira Júnior \\ Universidade São Judas Tadeu, São Paulo, SP, Brasil
}

\begin{abstract}
Aims: This study aimed to verify the relationship between of anthropometric and physical performance variables with game-related statistics in professional elite basketball players during a competition. Methods: Eleven male basketball players were evaluated during 10 weeks in two distinct moments (regular season and playoffs). Overall, 11 variables of physical fitness and 13 variables of game-related statistics were analysed. Results: The following significant Pearson's correlations were found in regular season: percentage of fat mass with assists $(\mathrm{r}=-0.62)$ and steals $(r=-0.63)$; height $(r=0.68)$, lean mass $(r=0.64)$, and maximum strength $(r=0.67)$ with blocks; squat jump with steals $(\mathrm{r}=0.63)$; and time in the T-test with successful two-point field-goals $(\mathrm{r}=-0.65)$, successful free-throws $(\mathrm{r}=-0.61)$, and steals $(\mathrm{r}=-0.62)$. However, in playoffs, only stature and lean mass maintained these correlations $(p \leq 0.05)$. Conclusions: The anthropometric and physical characteristics of the players showed few correlations with the game-related statistics in regular season, and these correlations are even lower in the playoff games of a professional elite championship, wherefore, not being good predictors of technical performance.
\end{abstract}

Keywords: anthropometric, physical performance tests, basketball, game-related statistics;

\section{Introduction}

Basketball has been described as an intermittent sport that is physically very demanding, requiring players to frequently repeat bouts of intense actions (sprinting, shuffling, jumping) with jogging, walking, or short periods of recovery ${ }^{1,2}$. Thus, elite basketball players show specific anthropometric ${ }^{3}$ and physical performance characteristics ${ }^{4}$ that can affect their game strategy and, consequently, their success in competitions. Therefore, a certain level of physical fitness is essential to the correct execution of a technique as well as to sustain the technical-tactical regimens required to achieve a high performance level ${ }^{5}$.

Trainers and coaches consider physical assessments and analyses of the technical-tactical performance of a team to be essential for successful improvements. However, it remains unclear how physical fitness is related to technical performance in elite basketball players.

Game-related statistics have been used worldwide for analyses of technical performances during games, and there are various criteria that define each indicator in order to ensure the objectivity of the observations and their quantification ${ }^{6}$. For instance, in basketball, the most winning teams are considered those with higher numbers of successful free-throws, rebounds ${ }^{7}$, and steals, and opponent's turnovers ${ }^{8}$.

On the other hand, few studies have focused on professional players during a competitive season, analyzing their anthropometric and physical adaptations in relationship with game-related statistics ${ }^{2,9-11}$. Particularly, no publications that have analyzed the performance of players in two distinct moments of the competition phase, i.e. regular season and playoffs, are available. A study that compared the physical (type of movements), physiological, and tactical demands of an elite under-18 Australian basketball team $(\mathrm{n}=8$ players $)$ noted that these demands were more pronounced during an official competition than in a friendly tournament ${ }^{12}$. Nevertheless, the study did not seek to identify relationship between the several variables and performance in the two competition types.

Given the expected effects over a season of training and competitions, are physical fitness alterations accompanied by changes in the technical performance of the game in elite 
players? Analyzing these variables can help the understanding of the relationship between physical fitness and technical performance in elite professional basketball players; moreover, such knowledge can possibly direct their training programs in future seasons. Thus, the objective of this study was to verify the relationship between of anthropometric and physical performance variables with the technical performance of elite professional basketball players. In agreement with previous publications, we hypothesized the presence of significant correlations of anthropometric and physical performance variables with the majority of game-related statistics at different times of the competition.

\section{Methods}

\section{Participants}

Eleven elite male basketball players participated in the present investigation (average age \pm standard deviation (SD): $25.1 \pm 4.3$ years, height: $195.4 \pm 11.3 \mathrm{~cm}$, body mass: $101.5 \pm 22.0 \mathrm{~kg}$, and training experience: $10.1 \pm 4.2$ years). The athletes belonged to a professional team of the State of São Paulo that competed in the Paulista State Basketball Championship (PSBC) in São Paulo (Brazil) and the Brazilian National Championship, organized by

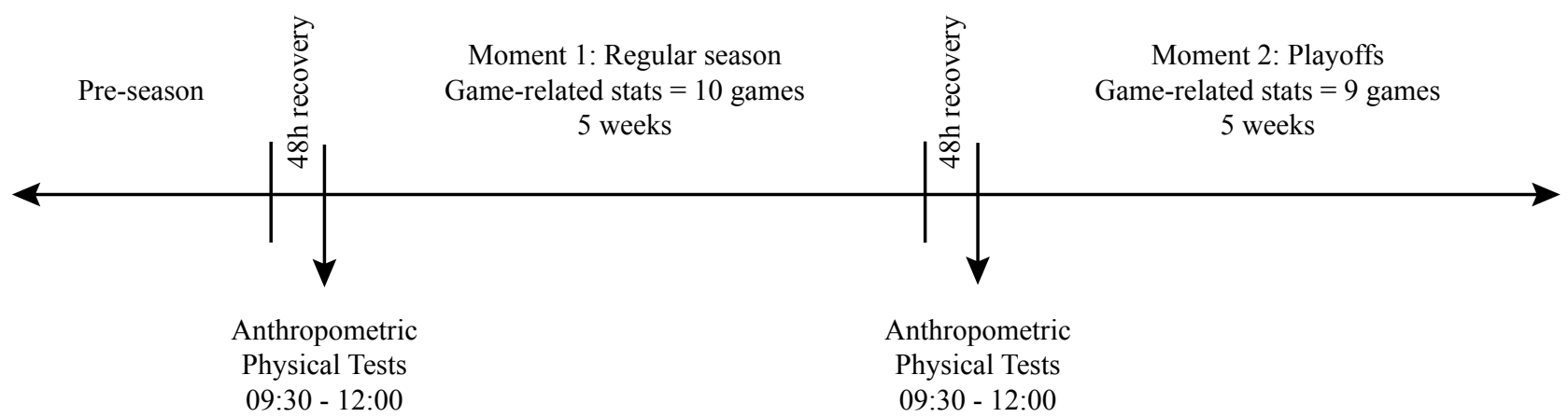

Figure I - Timeline of the moments of evaluation.

The evaluations were performed $48 \mathrm{~h}$ after a rest period. On the first day of evaluation, anthropometric variables, one-repetitionmaximum (1RM) test, and muscle power were measured. On the second day, the running tests were performed. All tests were performed in the morning between 9:30 am and 12:00 pm. The players were accustomed to the procedures and tests performed. All physical fitness evaluations were carried out in two consecutive training sessions by a single and experienced evaluator.

During the 10 weeks, 54 training sessions were performed. The training sessions focused on the development of physical condition were predominantly carried out at the basketball court. The technical-tactical training was based on small-sided games ${ }^{13}$ and 5vs5 in full and/or half-court, with a mean duration of 90 min per session. As the team was actually participating in a competition, the training sessions emphasized technical-tactical training, using basketball specific training means and methods. the National Basketball League (NBL). This team finished in second place in the NBL championship (season 2013/2014) and was composed of three guards, four forwards, and four centers. The analyses were carried out over 10 weeks, which included 10 regular season games and 9 playoff games of the PSBC. Players received information regarding the study and the associated risks; written informed consent was required for participation in the study. The study was conducted in accordance with the Declaration of Helsinki and was approved by the Research Ethics Committee of São Judas Tadeu University, process No. 639111/2014.

\section{Study design}

The physical fitness assessments in moment I (M1) were performed in the week prior to the beginning of the PSBC. M1 referred to the beginning of the regular season, and the values from M1 evaluations were used for relationship with game-related statistics of the regular season. In the 6th week (after 40 days), the physical fitness evaluations in moment II (M2) were conducted coinciding with the end of the regular season and the beginning of playoffs. M2 thus corresponded to the beginning of playoffs, and the values from M2 evaluations were used for relationship with game-related statistics of the playoffs. These timings for performing the physical fitness tests were chosen in accordance with the team coaches' planning and training protocols (Figure 1). 
Skin-fold thicknesses were obtained using Lange ${ }^{\circledR}$ callipers (Beta Technology Incorporated, USA) at the following seven sites: triceps, subscapula, midaxillary, anterior suprailiac, chest, abdomen, and thigh. The anatomical landmarks were identified and measurements were performed as described by Wilmore and Behnke ${ }^{14}$, with a median of three measurements used to represent skin-fold thickness. All measurements were performed by the same trained technician for all subjects. Body density and the percentage of body fat were determined according to athlete-specific equation described by Jackson and Pollock ${ }^{15}$.

\section{Physical Fitness Tests}

The subjects also underwent measurements of muscular power (vertical jumps) and strength (bench press 1RM), speed (20-m sprint), agility (T-test), and aerobic power (Yo-yo intermittent recovery test). Each player was instructed and verbally encouraged to produce maximal effort during all the tests. Standardized warm-up, consisting of jogging and a series of increasing intensity sprints, was performed before testing. No static stretching was allowed before testing. All field testing sessions were performed on the same basketball court where the players usually trained.

Maximal dynamic strength in bench-press exercise (BP) was recorded as the maximal weight (1RM) subjects were able to raise $^{16}$. The bar position for the free-weight bench-press exercise began in the up position at full elbow extension, moved to chest level for a momentary pause, and finished back at the starting position. Hand and foot positions were determined for each subject during familiarization and were held constant during all testing.

Vertical jump (VJ) performance was assessed using squat (SJ) and countermovement (CMJ) jumps according to the procedures suggested by Bosco, Luhtanen, and Komi ${ }^{17}$. The height of the leap was calculated based on the time of flight, using the Jump Test Pro ${ }^{\circledR}$ software (version 1.02), connected to a digital computer. All VJs were performed with hands held on the hips and attaining $90^{\circ}$ knee flexion at the start of the push-off phase. Players performed three trials of each jump, and the best of each jump mode was considered for analysis.

The participants also performed three maximal $20-\mathrm{m}$ sprints. During recovery (2-3 min), the participants walked back to the starting line and then waited for the next sprint. Times were recorded to the nearest one-hundredth of a second using timing gates (Cefise ${ }^{\mathrm{TM}}$, Brazil) placed $0.5 \mathrm{~m}$ above the ground ${ }^{18}$.

The T-test was administered using the protocol described by Semenick ${ }^{19}$. Three test trials were performed, and times were recorded to the nearest one-hundredth of a second using timing gates (Cefise ${ }^{\mathrm{TM}}$ ) placed $0.5 \mathrm{~m}$ above the ground. The subjects commenced the sprint when ready from a standing start $0.5 \mathrm{~m}$ behind the first timing gate. The reliability and validity of the T-test have been previously established ${ }^{20}$.

Bangsbo, Iaia, and Krustrup ${ }^{21}$ developed the Yo-yo intermittent recovery test (Yo-yo IR1) as a field test for assessing performance for team-sport players. The Yo-yo IR1 test consisted of $20-\mathrm{m}$ shuttle runs performed at increasing velocities with $10 \mathrm{~s}$ of active recovery between runs until exhaustion. The end of the test was considered when the participant twice failed to reach the front line in time (objective evaluation) or he felt unable to cover another shuttle at the dictated speed (subjective evaluation). The total distance covered during the Yo-Yo IR1 was recorded. The theoretical maximum oxygen consumption $\left(\mathrm{VO}_{2} \max \right)$ can be estimated for the Yo-Yo IR1 test from the following equation:

$\mathrm{VO}_{2} \max \left(\mathrm{mL} \cdot \mathrm{kg}^{-1} \cdot \mathrm{min}^{-1}\right)=\mathrm{IR} 1$ distance $(\mathrm{m}) \times 0.0084+36.4$

\section{Game-Related Statistics}

The game-related statistics were gathered live by PSBC official statisticians in accordance with criteria standardized by the International Federation of Basketball (FIBA) and the Brazilian Basketball Confederation (CBB). The analyses of the PSBC games were obtained on the official site and public domain of the PBF (Paulista Basketball Federation: http://www.fpb. com.br). The following absolute game-related statistics were gathered: points, three-point field goals, two-point field goals, free-throws, offensive rebounds, defensive rebounds, assists, steals, turnovers, blocks, fouls and playing time. The absolute individual stats values registered were transformed in average values, based on cumulative stats (sum of the individual stats for the championship phase) divided per game.

\section{Data analysis}

Data are expressed as mean \pm SD. The normality of the data was assessed by applying the Shapiro-Wilk test. Comparison between the mean values for M1 and M2 was performed using a paired Student's $t$-test. The effect size (ES) was used to analyse the anthropometric and metabolic variables, following the criteria of Cohen ${ }^{22}$, and the criteria of Rhea ${ }^{23}$ for the neuromuscular variables. Pearson's correlation coefficient was used to examine the relationship between the physical fitness of players and their game-related statistics. The magnitude of the correlation was considered as weak $(0.1<\mathrm{r}<0.3)$, moderate $(0.4<\mathrm{r}<0.6)$, and strong $(\mathrm{r}>0.7)$, according to Dancey and Reidy $^{24}$. The statistical package SPSS version 21.0 was used for statistical calculations. Significance was set at 0.05 .

\section{Results}

There was a significant reduction in fat mass (FM; of about $700 \mathrm{~g})$ and percentage of body fat $(\% \mathrm{BF})$ when comparing M1 and M2 values. The other anthropometry results remained similar between M1 and M2 (Table 1). The ES in all anthropometric variables was trivial $(\leq 0.20)$, except in $\% \mathrm{BF}$, where it was moderate. The evaluation of the physical components of strength, speed, agility, and aerobic power indicated improvements in all performance tests (Table 1) at M2. In the analysis of the ES for the variables of strength and power, a trivial ES $(\leq 0.25)$ and small ES $(0.25-0.50)$ was observed. The T-test and the $\mathrm{VO}_{2} \max$ presented moderate $\mathrm{ES}(0.50-0.80)$. Finally, the game-related statistics in the regular season and the playoff games presented no differences (Table 2). The ES observed 
in the game-related statistics variables was classified between trivial and small.

Table I - Anthropometric and physical performance characteristics of the professional basketball players at moment 1 and 2 evaluations. Data are presented as mean $\pm \mathrm{SD}$.

\begin{tabular}{lllll}
\hline $\boldsymbol{n}=\mathbf{1 1}$ & M1 & M2 & P & ES \\
\hline Body Mass $(\mathrm{kg})$ & $101.5 \pm 22.0$ & $100.4 \pm 20.4$ & 0.14 & 0.05 \\
\hline Lean Mass $(\mathrm{kg})$ & $86.9 \pm 16.4$ & $86.9 \pm 16.0$ & 0.99 & 0.00 \\
\hline Fat Mass $(\mathrm{kg})$ & $14.1 \pm 6.6$ & $13.4 \pm 5.2^{*}$ & 0.04 & 0.16 \\
\hline Body fat percentage $(\%)$ & $13.8 \pm 3.6$ & $13.1 \pm 2.8^{*}$ & 0.03 & 0.21 \\
\hline $\mathrm{SJ}(\mathrm{cm})$ & $33.4 \pm 5.2$ & $35.6 \pm 4.0^{*}$ & 0.00 & 0.42 \\
\hline $\mathrm{CMJ}(\mathrm{cm})$ & $39.3 \pm 5.6$ & $40.8 \pm 4.7^{*}$ & 0.03 & 0.26 \\
\hline BP $(\mathrm{kg})$ & $105.9 \pm 18.3$ & $108.5 \pm 17.9^{*}$ & 0.03 & 0.14 \\
\hline $20 \mathrm{~m} \mathrm{sprint}(\mathrm{s})$ & $3.24 \pm 0.22$ & $3.16 \pm 0.17^{*}$ & 0.01 & 0.38 \\
\hline Agility T-test $(\mathrm{s})$ & $9.28 \pm 0.46$ & $8.97 \pm 0.52^{*}$ & 0.00 & 0.68 \\
\hline VO max $\left(\mathrm{mL} \cdot \mathrm{kg}^{-1} \cdot \mathrm{min}^{-1}\right)$ & $46.7 \pm 2.8$ & $48.5 \pm 3.2^{*}$ & 0.00 & 0.62 \\
\hline & & & &
\end{tabular}

* Significant difference between M1 and M2 evaluations $(\mathrm{P}<0.05)$. Abbreviations: M1 - moment 1; M2 - moment 2; ES - effect size; SJ - squat jump; CMJ - counter movement jump; $\mathrm{BP}$ - 1RM Bench Press; $\mathrm{VO}_{2} \mathrm{max}-$ maximum oxygen consumption.

Table II - Game-related statistics of the professional basketball players during regular season (M1) and playoffs (M2). Data are presented as mean $\pm \mathrm{SD}$.

\begin{tabular}{lcccc}
\hline $\boldsymbol{n}=\mathbf{1 1}$ & M1 & M2 & P & ES \\
\hline Points & $7.8 \pm 6.5$ & $6.5 \pm 5.6$ & 0.09 & 0.21 \\
\hline Success three-points & $0.8 \pm 1.0$ & $0.7 \pm 0.8$ & 0.32 & 0.14 \\
\hline Success two-points & $1.7 \pm 1.4$ & $1.4 \pm 1.2$ & 0.20 & 0.19 \\
\hline Success free-throw & $2.0 \pm 2.5$ & $1.6 \pm 1.7$ & 0.34 & 0.16 \\
\hline Assists & $1.3 \pm 1.4$ & $0.9 \pm 0.9$ & 0.75 & 0.13 \\
\hline Offensive rebound & $0.7 \pm 0.5$ & $0.6 \pm 0.4$ & 0.81 & 0.08 \\
\hline Defensive rebound & $1.9 \pm 1.0$ & $1.8 \pm 1.0$ & 0.75 & 0.10 \\
\hline Total rebounds & $2.6 \pm 1.4$ & $2.5 \pm 1.2$ & 0.07 & 0.32 \\
\hline Steals & $0.7 \pm 0.7$ & $0.4 \pm 0.3$ & 0.09 & 0.44 \\
\hline Fouls & $2.0 \pm 1.0$ & $1.9 \pm 0.8$ & 0.57 & 0.17 \\
\hline Turnovers & $1.3 \pm 0.9$ & $1.1 \pm 0.7$ & 0.53 & 0.16 \\
\hline Blocks & $0.2 \pm 0.2$ & $0.1 \pm 0.2$ & 0.10 & 0.24 \\
\hline Playing time (min) & $15.6 \pm 8.5$ & $16.5 \pm 9.0$ & 0.58 & 0.11 \\
\hline
\end{tabular}

Abbreviations: M1 - moment 1; M2 - moment 2; ES - effect size

During the regular season, the athletes with less $\% \mathrm{BF}$ were prone to provide more assists $(\mathrm{r}=-0.62, p=0.043)$ and steals $(\mathrm{r}=-0.63, p=0.034)$, whereas athletes with higher lean mass
(LM) generated fewer turnovers $(\mathrm{r}=-0.63, p=0.038)$. Athletes with greater height $(\mathrm{r}=0.68, p=0.002)$ and LM $(\mathrm{r}=0.64$, $p=0.002)$ tended to provide more blocks in games. The neuromuscular component (maximum strength and muscular power) also correlated significantly with blocks (BP; $r=0.67$, $p=0.035$ ) and steals (SJ jump; $\mathrm{r}=0.63, p=0.038$ ). Finally, the agility, expressed by the time required to complete the T-test, was associated with successful two-point field goals $(\mathrm{r}=-0.65$, $p=0.030)$, successful free-throws $(\mathrm{r}=-0.61, p=0.044)$, and steals $(\mathrm{r}=-0.62, p=0.043)$.

In the playoff games, stature and lean mass increased their degree of relationship with blocks $(\mathrm{r}=0.76, p=0.007$; and $\mathrm{r}=0.70, p=0.017$, respectively). The body mass, BP, CMJ, 20 m-sprint, $\mathrm{VO}_{2} \max$, points, offensive rebounds, defensive rebounds, fouls, and playing time presented weak $(<0.40)$ or not significant $(p>0.05)$ relationship with each other and were therefore not described.

\section{Discussion}

The main finding of this study is that the physical fitness improvement identified between the two phases of the competition was not accompanied by changes in the technical performance, given that the few correlations of anthropometric variables and physical performance with game-related statistics observed in the regular season were reduced in the playoff games. Although significant improvements in physical fitness were observed between the M1 and M2 assessments, the ES found in these variables was predominantly trivial and small.

Paiva Neto and César ${ }^{25}$ noted that players with greater FM and $\% \mathrm{BF}$ can present a drop in local muscular endurance and speed in various actions during games. This may explain the fact that players with lower $\% \mathrm{BF}$ and greater agility were able to achieve more numerous steals from opponents in our study. In a study performed with the Brazilian women's national basketball team, Nunes ${ }^{11}$ found negative correlations of body mass index and $\% \mathrm{BF}$ with playing time as well as with the total points. These data, however, were not corroborated in our study, since no significant correlations were noted between playing time or total points and any of the anthropometric variables.

De Rose Jr, Tavares, and Gitti ${ }^{26}$ highlighted the stature and LM of basketball players as being necessary for successful blocks. According to the authors, the center position players are those who achieve a higher number of blocks. The assertions of these authors are consistent with our findings, since both variables (height and LM) were correlated with a greater occurrence of blocks in matches, regardless of the competition phase.

The BP showed significant correlation only with the blocks and only in the regular season. In the literature, we did not find any relationship between the maximum strength in BP and game-related statistics. This lack of correlation is possibly due to the low specificity of BP with basketball motor skills. On the other hand, in a study involving professional Bosnia basketball players, Pojskić, Šeparović, Muratović, and Užičanin ${ }^{27}$ revealed that in muscle power tests of the upper limbs, which resembles the basketball motor skills, such as medicine ball throws, a 
significant correlation was observed with the accuracy of threepoint field goals during competition.

The correlations between lower limbs power and game-related statistics only displayed a significant result between $\mathrm{SJ}$ and steals, and even so, this was noted exclusively in the regular season. This result is of particular interest, because it was expected that this performance could express, at least in part, the performance of blocks and rebounds, according to the specificity of the movement. The jump without countermovement resembles some game situations, such as squatting position for the box out before to dispute a rebound. Even without significant differences between $\mathrm{M} 1$ and $\mathrm{M} 2$, the number of steals in the playoff games decreased considerably (almost 50\%), and this was due to two specific players, which showed values above the team average in M1 (large heterogenity). In M2, they equaled the mean, reducing the degree of relationship between SJ and steals. In this case in particular, we believe more in a casual effect than other possible reason.

Three tests involving displacements were performed to measure the short-sprint time in a straight line, agility, and maximum oxygen consumption. Although speed and aerobic power are well-known pertinent factors affecting the performance of players of team sports, in our study, only agility was related with particular game-related statistics (two-point field goals, successful free-throws and steals). According to McGill et al. ${ }^{10}$, players with greater agility remain playing longer and performing a greater number of points, assists, and steals. We speculate that this relationship between agility and field goals found in our study is due to several movements that occur in offensive situations, especially before the short - and mid-distance throws, which predominate in the game $\mathrm{e}^{28}$. Thus, these movements are based on sudden changes in direction and speed variations. The same principle applies to defensive moves associated with steals.

Interestingly, the playing time was not correlated with any of the studied variables in our study. In contrast, females basketball players with higher $\mathrm{VO}_{2} \max$ were noted to play for longer durations ${ }^{12}$. Similarly, low to moderate correlations were observed between components of anaerobic power and the playing time in university players ${ }^{29}$. The unexpected results in the present study led us to speculate that the greatest determinant of the permanence of professional players in the game is the perception of the coach about their ability and game efficiency rather than their physical condition. However, in the absence of details regarding the training strategies and coaching philosophy, we cannot confirm this conclusion. During a game, the coach changes the style of the team according to the physical condition of his players, the opponents, or the specific circumstances of a game. Such strategic differences in the match style can have a great impact on the physiological requirements and training schemes, causing the relationship between physical fitness and technical performance to be unclear ${ }^{30}$.

During the regular season, as most players in the team were still developing their physical condition for the competition, we believe that the coach may have performed substitutions during games based on the physical condition of each player at that moment, allowing a greater rotation between them.

We were unable to identify any studies that have evaluated correlations between physical tests and game-related statistics in two distinct moments of a competition in the literature. In under-16 Croatian male athletes, no correlation was noted between the performance of physical fitness tests and gamerelated statistics ${ }^{31}$. Pojskić et al. ${ }^{27}$ used regression analysis to demonstrate weak or non-existent relations between physical performance tests and shooting accuracy among professional Bosnian basketball players. Ostojic et al ${ }^{30}$ pointed out that the success of the teams, discriminated by physical conditioning alone, seems to be insufficient for understanding the technical and tactical performances and ensure excellence in this modality.

In the present study, few relationship were observed between physical condition and technical performance of the game, especially in the playoffs. The hypotheses that countless correlations exist for anthropometric characteristics and physical performance tests with game-related statistics were not sustained by this study. Therefore, we speculate that the decrease in significant correlations from M1 to M2 could be due two main reasons: 1) the differences between the demands of the regular season and playoffs; 2) the high level of heterogeneity on the game-related statistics. It is important to note that the large heterogeneity observed in some game-related statistics variables led us to take casual effect on some correlations observed in M1, hindering even more the understanding of the relationship between these variables with the physical performance.

Although we did not identify stability in the relationship between the physical and technical performances of the game in the two evaluation moments, we believe that the improvements in the physical fitness levels during the season are essential for the satisfactory performance of the athletes, allowing optimal conditions for performing their functions within the game, regardless of technical errors and corrections.

Our study has certain limitations as follows: (a) impossibility of other evaluation moments; (b) and a small sample size. However, the players included in the present study are considered to be a representative sample of professional elite basketball play$\mathrm{ers}^{28}$, which allows the observation of the behavior of physical and technical performance variables during a competition for an elite national team, which is rare in the sport sciences ${ }^{31,32}$.

\section{Conclusion}

The anthropometric and physical characteristics of the players showed few correlations with the game-related statistics in regular season, and these correlations are even lower in the playoff games of a professional elite championship, wherefore, not being good predictors of technical performance. Among the physical demands imposed by the game, agility was one of the most important physical fitness characteristics, especially in relationship with the technical performance indicators of the game, such as shooting and steals during the regular season of the championship.

\section{References}

1. Drinkwater EJ, Pyne DB, McKenna MJ. Design and interpretation of anthropometric and fitness testing of basketball players. Sports Med. 2008;38(7):565-78. 
2. Conte D, Favero TG, Lupo C, Francioni FM, Capranica L, Tessitore A. Time-motion analysis of Italian elite women's basketball games: Individual and teamanalyses. JStrength CondRes. 2015;29(1):144-50.

3. Ben Abdelkrim N, El Fazaa S, El Ati J. Time-motion analysis and physiological data of elite under-19-year-old basketball players during competition. Br J Sports Med. 2007;41(2):69-75.

4. Hoffman JR, Epstein S, Einbinder M, Weinstein Y. A comparison between the wingate anaerobic power test to both vertical jump and line drill tests in basketball players. J Strength Cond Res. 2000;14(3):261-64.

5. Moreira A. Testes de campo para monitorar desempenho, fadiga e recuperação em basquetebolistas de alto rendimento. Rev Educ Fís/UEM. 2008;19(2):241-50.

6. FIBA. Official Basketball Statisticians' Manual 2012. http:// www.fiba.com/downloads/Miscellaneous/FIBA_Stats_ Manual20120920.pdf; 2012 [cited 2016 march, 23th].

7. Ibanez SJ, Sampaio J, Feu S, Lorenzo A, Gomez MA, Ortega E. Basketball game-related statistics that discriminate between teams'season-long success. Eur J Sport Sci. 2008;8(6):369-72.

8. Sampaio J, Drinkwater EJ, Leite NL. Effects of season period, team quality, and playing time on basketball player's game-related statistics. Eur J Sport Sci. 2010;10(2):141-9.

9. Gomes JH, Chaves RC, Evangelista A, Charro MA, Bocalini DS, Figueira Jr AJ. Relação entre antropometria, desempenho físico e estatística de jogo em jogadores jovens de elite de basquetebol. Rev Bras Ciênc Mov. 2015;23(2):66-73.

10. McGill SM, Andersen JT, Horne AD. Predicting performance and injury resilience from movement quality and fitness scores in a basketball team over 2 years. J Strength Cond Res. 2012;26(7):1731-9.

11. Nunes JA. Seleções olímpicas de basquetebol feminino do Brasil (2000 e 2004): correlação entre variáveis técnicas e físicas. Campinas. Dissertação [Mestrado em Educação Física] - Universidade Estadual de Campinas; 2007.

12. Klusemann MJ, Pyne DB, Hopkins WG, Drinkwater EJ. Activity profiles and demands of seasonal and tournament basketball competition. Int J Sports Physiol Perform. 2013;8(6):623-9.

13. Halouani J, Chtourou H, Gabbett T, Chaouachi A, Chamari K. Small-sided games in team sports training: a brief review. J Strength Cond Res. 2014;28(12):3594-618.

14. Wilmore JH, Behnke AR. An anthropometric estimation of body density and lean body weight in young men. J Appl Physiol. 1969;27(1):25-31

15. Jackson AS, Pollock ML. Generalized equations for predicting body density of men. Br J Nutr. 1978;40:497-504.

16. Weiss LW, Wood LE, Fry AC, Kreider RB, Relyea GE, Bullen DB, et al. Strength/power augmentation subsequent to short-term training abstinence. J Strength Cond Res. 2004;18:765-70.

17. Bosco C, Luhtanen P, Komi PV. A simple method for measurement of mechanical power in jumping. Eur J Appl Physiol Occup Physiol. 1983;50(2):273-82.

18. Scanlan AT, Tucker PS, Dalbo VJ. A comparison of linear speed, closed-skill agility, and open-skill agility qualities between backcourt and frontcourt adult semiprofessional male basketball players. J Strength Cond Res. 2014;28(5):1319-27.

19. Semenick D. The T-test. NSCA J. 1990;12:36-7.

20. Pauole K, Madole K, Garhammer J, Lacourse M, Rozenek R. Reliability and validity of the T-test as a measure of agility, leg power, and leg speed in college-aged men and women. J Strength Cond Res. 2000;14(4):443-50.
21. Bangsbo J, MohrM,PoulsenA,Perez-GomezJ,KrustrupP. Training and testing the elite athlete. J Exer Sci Fitness 2006;4(1):01-14.

22. Cohen J. A power prime. Psych Bull. 1992;112(1):155-9.

23. Rhea MR. Determining the magnitude of treatment effects in strength training research through the use of the effect size. J Strength Cond Res. 2004;18(4):918-20.

24. Dancey C, Reidy J. Estatística sem matemática para psicologia: usando SPSS para windows. Porto Alegre: Ed. Artmed; 2006.

25. Paiva Neto A, César MC. Avaliação da Composição Corporal de Atletas de Basquetebol do Sexo Masculino Participantes da Liga Nacional 2003. Rev Bras Cinean Des Hum. 2005;7(1):35-44.

26. De Rose D, Tavares AC, Gitti V. Perfil técnico de jogadores brasileiros de basquetebol: relação entre os indicadores de jogo e posições específicas. Rev Bras Educ Fís Esp. 2004;18(4):377-84.

27. Pojskić H, Šeparović V, Muratović M, Užičanin E. The relationship between physical fitness and shooting accuracy of professional basketball players. Motriz. 2014;20(4):408-17.

28. Meneses LR, Gois Jr LEM, Almeida MB. Análise do desempenho do basquetebol brasileiro ao longo de três temporadas do Novo Basquete Brasil. Rev Bras Ciênc Esporte 2016;38(1):93-100.

29. Hoffman JR, Tenenbaum G, Maresh CM, Kraemer WJ. Relationship between athletic performance tests and playing time in elite college basketball players. J Strength Cond Res. 1996;10(2):67-71.

30. Ostojic SM, Mazic S, Dikic N. Profiling in basketball: physical and physiological characteristics of elite players. J Strength Cond Res. 2006;20(4):740-44.

31. Gonzalez AM, Hoffman JR, Rogowski JP, Burgos W, Manalo E, Weise K, et al. Performance changes in NBA basketball players vary in starters vs. nonstarters over a competitive season. J Strength Cond Res. 2013;27(3):611-5.

32. Manzi V, D'Ottavio S, Impellizzeri FM, Chaouachi A, Chamari K, Castagna C. Profile of weekly training load in elite male professional basketball players. J Strength Cond Res. 2010;24(5):1399-406.

\section{Acknowledgements}

The authors would like to thank all the players for their time and participation. Much gratitude is also reserved for the coaches and physiotherapists for their assistance and enthusiasm towards the project.

\section{Funding information}

There was any public or private financing to carry out the all or part of the work for the manuscript.

\section{Corresponding author}

João Henrique Gomes

Universidade São Judas Tadeu, São Paulo, Sp, Brasil

Email: jhenriquegomes@terra.com.br

Manuscript received on September 22, 2016

Manuscript accepted on November 29, 2016

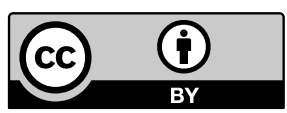

Motriz. The Journal of Physical Education. UNESP. Rio Claro, SP, Brazil - eISSN: 1980-6574 - under a license Creative Commons - Version 3.0 


\section{Erratum}

In the article "Relationship between physical fitness and game-related statistics in elite professional basketball players: Regular season vs. playoffs”, published in volume 23, number 2, 2017, DOI: 10.1590/s1980-6574201700020004, and identification: e101626.

Aylton José Ferreira Júnior

Should read:

Aylton José Figueira Júnior 